\title{
ANALYSIS OF A SIMPLIFIED METHOD FOR DETERMINING FATIGUE CHARTS $\Delta S$ - $N$ ON THE EXAMPLE OF WELDED AND SOLDERED CONNECTORS
}

\author{
Grzegorz Szala \\ Bogdan Ligaj \\ University of Technology and Science in Bydgoszcz, Poland
}

\begin{abstract}
The paper describes the method of determining fatigue charts $\Delta S-N$, which is particularly useful in the description of fatigue properties of welded and soldered joints. This method is based on IIW (International Institute of Welding) guidelines and FITNET procedures. This method makes it possible to design $\Delta S-N$ charts in a probabilistic approach, which is important in the reliability analysis of structural elements. The work also contains examples of charts resulting from the development of test results for selected welded and soldered joints.
\end{abstract}

Keywords: fatigue durability, S-N diagram, FITNET, bonded joints.

\section{INTRODUCTION}

Materials fatigue properties research is time-consuming and cost-intensive. The time of their implementation and costs depend mainly on the purpose of the research, including the complexity of the research objects. The natural large spread of fatigue test results requires numerous repetitions of tests required due to their correct statistical evaluation.

In the fatigue calculations of construction elements, fatigue properties descriptions are used in the form of fatigue charts. Depending on the level of loads, these charts are determined in the scope of:

- low cycle fatigue (LCF - Low Cycle Fatigue), in which plastic deformations in the fracture zones predominate in energetic [1] or deformation [2],

- high cycle fatigue (HCF - High Cycle Fatigue), in which elastic deformation in the fracture zones dominates - in stress terms [3].

The subject of the analysis in the presented work are diagrams of fatigue life in terms of stress, used in the calculation of durability of welded structural elements.

The basic characteristic describing the fatigue properties of materials and machine construction elements is the fatigue life $\Delta S$ - $N$ diagram (referred to as the Wöhler chart) [4], which is determined on the basis of fatigue tests carried out under variable sinusoidal loads - constant amplitudes at different levels of amplitude of stress changes. For most structural steels, these diagrams are determined in two ranges: limited and unlimited fatigue life (usually described by the number of sinusoidal cycles to fatigue crack). In the mentioned ranges, different test methods and the development of test results are used. In terms of limited fatigue life, tests are carried out on several levels of stress amplitude (usually more than 5) in a few repetitions at each level (4-5), while in the range of unlimited fatigue life (so-called limit of fatigue) the test is carried out using one of the following methods: step method or Probit method and its derivatives, which are described in the basic literature, among others [4].

It is easy to calculate that in scientific studies, which aim to determine the $\Delta S-N$ chart in probabilistic terms, testing 30 samples in each range, at $20 \mathrm{~Hz}$, the total time of a 24-hour net research will be about 4,000 hours, which corresponds to a 6 month period. This time is appropriately extended by adding auxiliary time for making samples, programming endurance machines etc.

The cost of research is significantly influenced by, among others, the time of their implementation, the cost of working hours of test equipment, the performance of test facilities proportional to their quantity, the cost of tooling and the development of test results.

The above estimates indicate the need to strive to reduce the time required for fatigue tests. This limitation can be obtained 
by limiting the number of samples tested and searching for simplified fatigue testing methods.

In the first case, especially in technical and comparative tests, fatigue properties of objects with different characteristics (different manufacturing technologies, optimization of structural features, etc.), fatigue charts are determined on a smaller number of samples, e.g. according to the standard [12].

The group of simplified methods can include experimentalstatistical methods in which the $\Delta S-N$ graphs are used to describe the results of experiments for a characteristic point of the graph and statistical data from studies of a similar class of objects given in literature and catalogs, e.g.: [5], [6] and [7]. An overview of this type of methods is presented in [3] and [8].

In the absence of fatigue test results, fatigue charts can be determined with a small approximation, based on the statistical data of the $\Delta S-N$ graphs of the objects described in the literature. These data are selected based on the results of mechanical properties tests under monotonic load conditions. Such charts are used only in the initial phases of designing structural elements.

The issue described in this paper is more complex in the case of welded joints and machine construction elements. This complexity results mainly from: complex constructional features, heterogeneity of structure and high level of welding stresses in welded joint zones. These issues were the topic of the works $[9,17,18,19,20]$. The description of fatigue properties was based, in these cases, on the determined, simplified fatigue charts $\Delta \mathrm{S}-\mathrm{N}$ given in the catalogs of ship classification societies, IIW documents and in the annex to FITNET procedures. In these materials, the parameters of $\Delta S-N$ charts are assigned to individual elements of welded structures (elementary nodes, welded joints). These charts belong to the group of simplified experimental-statistical charts.

Strength and fatigue durability is one of the groups of problems that have an impact on the construction of large structural components. These include the elements of seagoing ships. Paper [13] presents several ways to assess the durability of fatigue hull structural elements. In practice, some approaches based on nominal stresses or hot spots are used, which form the basis for determining fatigue life using the $\Delta S-N$ reference curves.

Hot spot is a point on the edge of the weld, where a fatigue crack is expected. Structural stresses ("hot spot stress") take into account the effect of increased stress caused by the geometry of the weld joint. They depend on the geometrical dimensions and load method. The method of determining "hot spot stress" is presented in the works $[15,16]$.

Paper [14] presents a comparison of fatigue characteristics of twenty selected materials. The adjustment of durability charts to the results of experimental tests was determined on the basis of the value of the determination coefficient. It was determined that fatigue life (directional factor of the straight line) is influenced by many factors, including the form of sample damage.

The aim of this study is to present the method of fatigue $\Delta S-N$ determination based on the determination of the characteristic point (fatigue strength for $N=2 \cdot 10^{6}$ cycles) and the directional coefficient of the straight line described by parameter $m$ in the mathematical description of the $\Delta S-N$ plot [6 ]. The $m$ parameter is the exponent of the power of the equation describing the fatigue life chart.

The scope of work includes formulation of the problem (description of the method) and examples of plotting $\Delta S-N$ for selected structural bonded nodes in the range of high cycle fatigue (HCF) and the limit of fatigue (FL).

\section{FORMULATION OF THE PROBLEM}

Examples of $\Delta S-N$ fatigue charts are shown in Figure 1, where Figure 1a - shows the general chart, and Figure $1 \mathrm{~b}$ - an example of a chart for a cross weld joint (transverse butt welds at crossing flanges, crack starting at butt weld, welded from both sides and misalignment $<10 \%$ ) [6].

a)

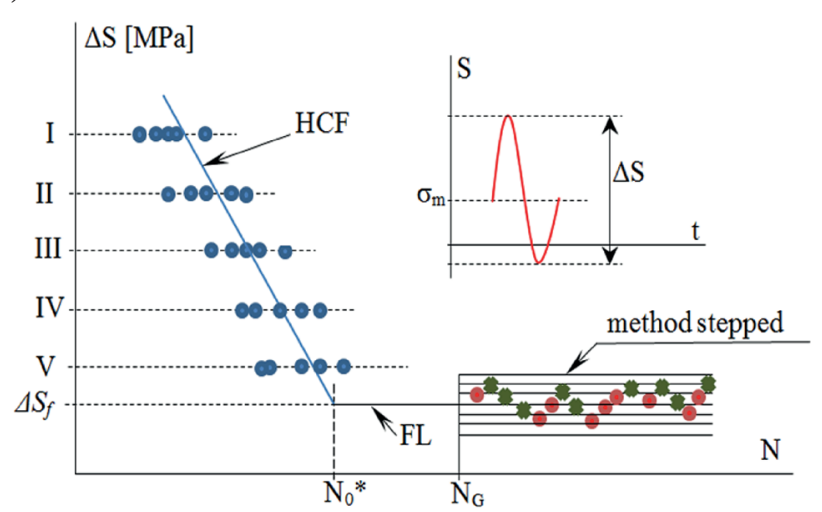

b)

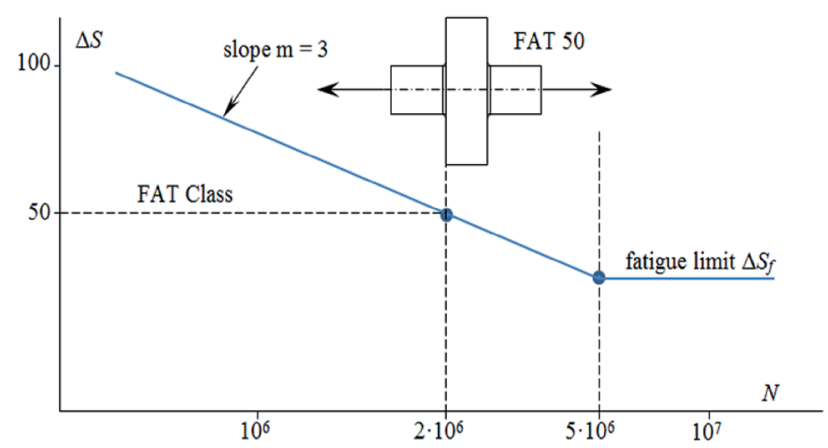

Fig. 1. Fatigue chart $\Delta S-N$ : a) a schematic presentation of the $\Delta S-N$ diagram determined on the basis of test results,

b) an example of a fatigue chart according to FITNET procedures [6]

Figure la is a schematic diagram of fatigue $\Delta S-N$ with basic parameters. The chart in the range of limited fatigue life of HCF is determined based on the results of studies using statistical straight line regression theory, while in the range of the LF fatigue limit according to e.g. the step method. These methods are described, among others, in monograph [4].

The form of the $\Delta S-N$ chart is described by the following formulas: 


$$
\text { - in HCF range }
$$

$$
\frac{\Delta S^{m}}{N}=C \quad \text { for } \Delta S>\Delta S_{f}
$$

or in a bilogarithmic form

$$
\begin{array}{ll}
\log \Delta S=-\frac{1}{m} \log N+c & \text { for } \Delta S>\Delta S_{f} \\
- \text { in LF range } & \\
N \rightarrow \infty & \text { for } \Delta S \leq \Delta S_{f}
\end{array}
$$

Of course, in a bilogarithmic system $(\log \Delta S, \log N)$, the line displaying the formula (2) is a straight line, to determine which it is enough to know the position of two points belonging to it or one point and the directional coefficient of the line described by the parameter $m$.

The second of these cases in the determination of $\Delta S-N$ charts was based on FITNET procedures [6] - Fig. 1b. The characteristic point belonging to the $\Delta S-N$ chart is the strength of the welded joint or welded structural element corresponding to the limited durability $N=2 \cdot 10^{6}$ (referred to as FATclass), and the $m$ value defining the directional coefficient for welded joints from the statistical analysis of numerous tests -3 were assumed, for normal stresses or 5 for tangential stresses. For the so determined charts in the HCF range, the LF fatigue limit is determined by taking the chart refraction point for $N_{0}=5 \cdot 10^{6}$ (normal stresses) or $N_{0}=10^{8}$ cycles (shear stresses).

The value of the FAT parameter is determined by two methods presented graphically in Fig. 2. The first method (Fig. 2a) consists in the experimental determination of the chart in the HCF range and reading the FAT value from the formula (2). The second method is to determine the FAT values using the methods used to determine the LF fatigue limit (e.g. step or Probit method) assuming the base number of $N_{F A T}=2 \cdot 10^{6}$ cycles (Fig. $2 \mathrm{~b}$ ).

a)

b)
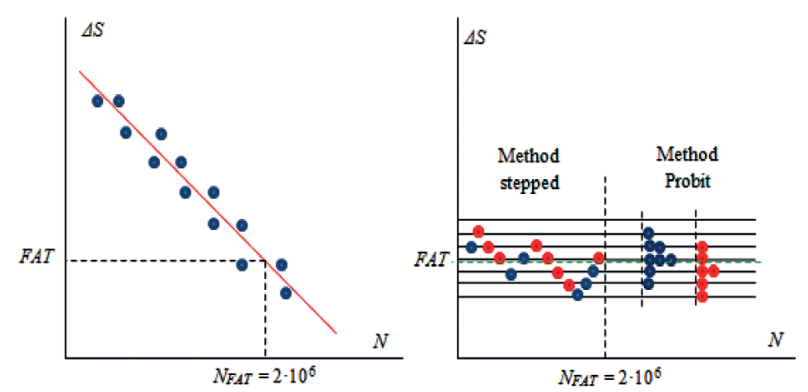

Fig. 2. Schematic representation of the methods for determining the FAT parameter: a) based on the results of fatigue tests in the HCF range, b) based on the results of fatigue tests in the LF range.
In the examples analyzed in this paper the abovedescribed method of plotting $\Delta S-N$ charts according to FITNET procedures was adopted, in which the FAT value was determined by statistical methods based on fatigue test results. Similarly, the experimentally determined limit values for fatigue limit enable the analysis of the degree of simplification resulting from the method described in FITNET procedures. In addition, a probabilistic approach to the FAT and $\Delta S_{f}$ parameter enables the $\Delta S-N$ chart to be determined for a wide range of fatigue crack failure.

\section{DETERMINATION OF THE $\Delta S$ - $N$ FATIGUE CHART FOR THE SELECTED WELDED TUBULAR NODE}

To analyze the problem of determining the $\Delta S-N$ chart according to the method described in point 2 , the welded pipe joint shown in Fig. 3 was selected.

\section{CONSTRUCTION FEATURES \\ OF THE WELDED JOINT}

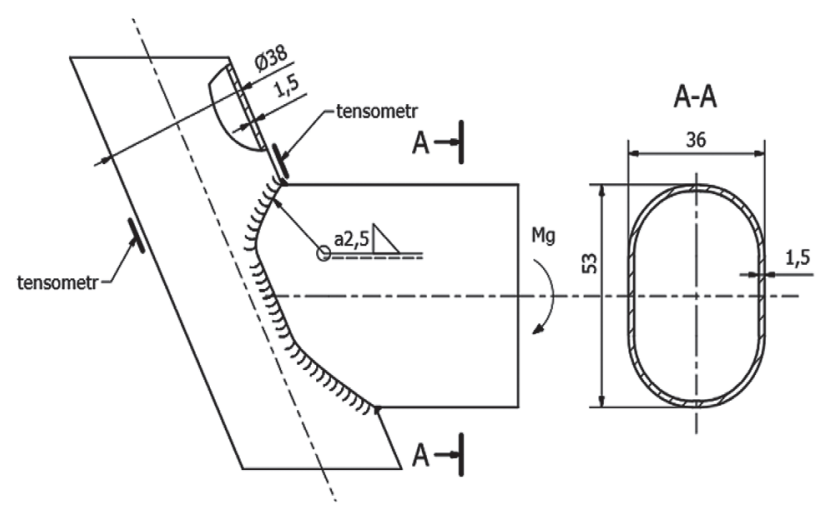

Fig. 3. Tubular welded joint

The joint was made of calibrated tubes welded by hand. The pipes are made of $10 \mathrm{Bx}$ steel with the following chemical composition: $(0,09 \div 0,15) \mathrm{C},(0,35 \div 0,6) \mathrm{Mn}$ and maximum: 0,03 Si, 0,004 P and 0,004 S. Fillet welds were made with a thickness of $\mathrm{a}=2.5 \mathrm{~mm}$. The tensile strength of the pipe material was $R_{m}=473 \mathrm{MPa}$ and the yield point $R_{0,2}=400 \mathrm{MPa}$.

\section{RESULTS OF FATIGUE TESTS}

The fatigue tests of the joint shown in Fig. 3 were performed to determine the $\Delta S-N$ chart in two ranges: in the HCF range

\begin{tabular}{|c|c|c|c|c|c|c|c|c|c|c|}
\hline Stress range $[\mathrm{MPa}]$ & 90 & 96 & 102 & 112 & 124 & 132 & 146 & 156 & 160 & 200 \\
\hline Number of cycles to $\operatorname{crack} N \cdot 10^{-4}$ & 20,0 & 19,2 & 3,84 & 3,42 & 2,50 & 3,10 & 2,35 & 1,27 & 1,30 & 0,42 \\
\hline
\end{tabular}
(according to Fig. 2a), and in the LF range (according to Fig. 2b) assuming a $N_{F A T}=2 \cdot 10^{6}$ cycles base. The results of HCF research are summarized in Table 1.

Tab. 1. Results of fatigue tests of a welded joint under constant amplitude load in the HCF range 
The regression equation determined on the basis of the results from Table 1 for the HCF range according to the formula (2) has the form

$$
\log \mathrm{DS}=-0,203 \log \mathrm{N}+3,014
$$

which in graphical form is shown in Figure 4.

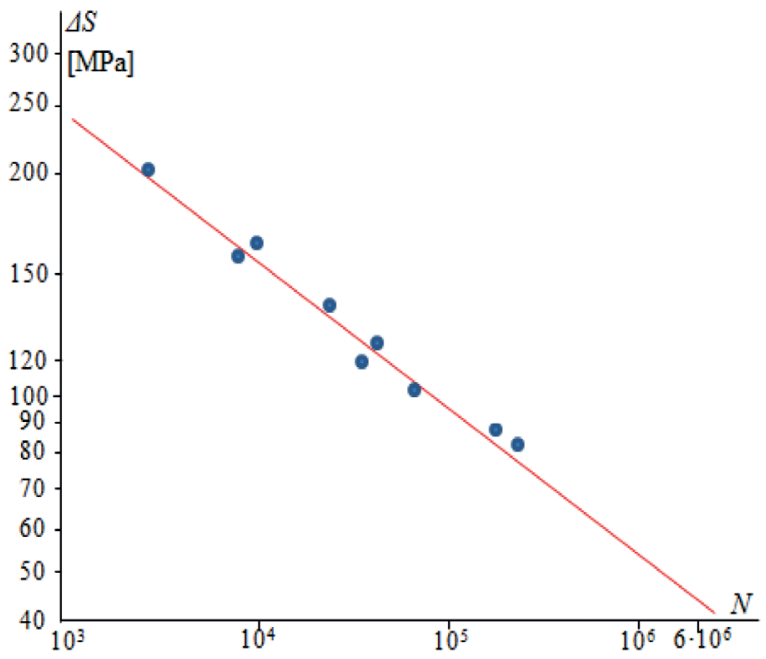

Fig. 4. Fatigue diagram $\Delta S-N$ of the welded joint in the HCF range

The Probit method test results of the LF range are presented in Table 2.

Tab. 2. Results of fatigue tests of a welded joint using the Probit method

\begin{tabular}{|c|c|c|c|c|c|}
\hline $\boldsymbol{i}$ & $\Delta S_{\boldsymbol{i}}$ & $\boldsymbol{t}_{\boldsymbol{i}}$ & $\boldsymbol{m}_{\boldsymbol{i}}$ & $\boldsymbol{n}_{\boldsymbol{i}}$ & $\boldsymbol{g}_{\boldsymbol{i}}$ \\
\hline $\mathbf{1}$ & 2 & 3 & 4 & 5 & 6 \\
\hline $\mathbf{1}$ & 75 & 2 & 0 & 2 & 0 \\
\hline $\mathbf{2}$ & 80 & 2 & 1 & 3 & 0,33 \\
\hline $\mathbf{3}$ & 85 & 3 & 2 & 5 & 0,40 \\
\hline $\mathbf{4}$ & 90 & 2 & 2 & 4 & 0,50 \\
\hline $\mathbf{5}$ & 95 & 1 & 2 & 3 & 0,66 \\
\hline $\mathbf{6}$ & 100 & 0 & 2 & 2 & 1,0 \\
\hline
\end{tabular}

Explanations: $i$ - stress level number in the area of Probit method test $\Delta S_{i}$-range at $i$-th level, $t_{i}$ - number of undamaged joints to the basic number of cycles at the $i$-th level, $m_{i}$ - number of joints with fatigue cracks at the $i$-th level, $n_{i}$ - the number of joints tested at the $i$-th level, $g_{i}$ - the frequency of joints cracks at the $i$-th level

The average value of fatigue strength for the base number of $N_{F A T}=2 \cdot 10^{6}$ cycles and the standard deviation are respectively: $\Delta S_{F A T}=88 \mathrm{MPa}$ and $S_{F}=20 \mathrm{MPa}$, which is illustrated in Fig. 5 .

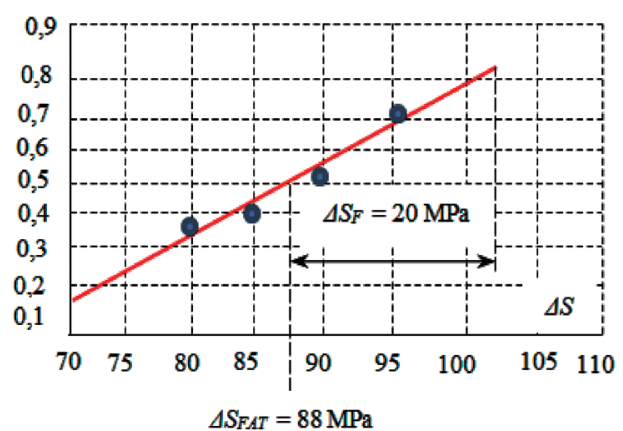

Fig. 5. Distribution of the FAT parameter of a welded joint determined by the Probit method

\section{EXAMPLES OF FATIGUE TEST RESULTS OF BONDED TUBULAR NODES}

Further examples of fatigue test results of welded tubular joints, described in this section, are appropriate to the subject and purpose of the article by the development of many years of research carried out in the laboratory of the University of Science and Technology in Bydgoszcz. These data are summarized in tabular form (Table 3).

In the joint diagrams (col. 2), fatigue crack initiation sites were marked. Column 3 gives a short description of the joints, parameters of the experimental fatigue chart $\Delta S-N\left(N_{0}^{*}, m\right)$ and number of fatigue tests $n$ performed. Mean $\mathrm{FAT}_{50}$ values are shown in column 4 , while standard deviations $s_{F}$ and values of the coefficient of variation are included in columns 5 and 6 .

\section{ANALYSIS OF TEST RESULTS}

The list of fatigue $\Delta S-N$ charts determined experimentally on the basis of the test results described in point 3 , and determined in accordance with FITNET procedures according to Fig. 2a and Fig. 2b, is shown in Fig. 6.

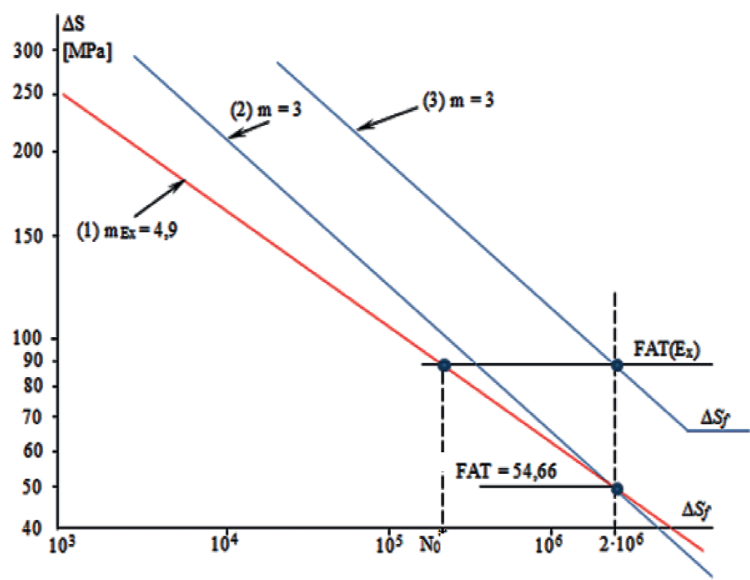

Fig. 6. Fatigue charts: 1- experimental, 2- according to FITNET and HCF procedures, 3- according to FITNET procedures and experimentally determined parameter 
Tab. 3. Examples of welded tubular construction joints

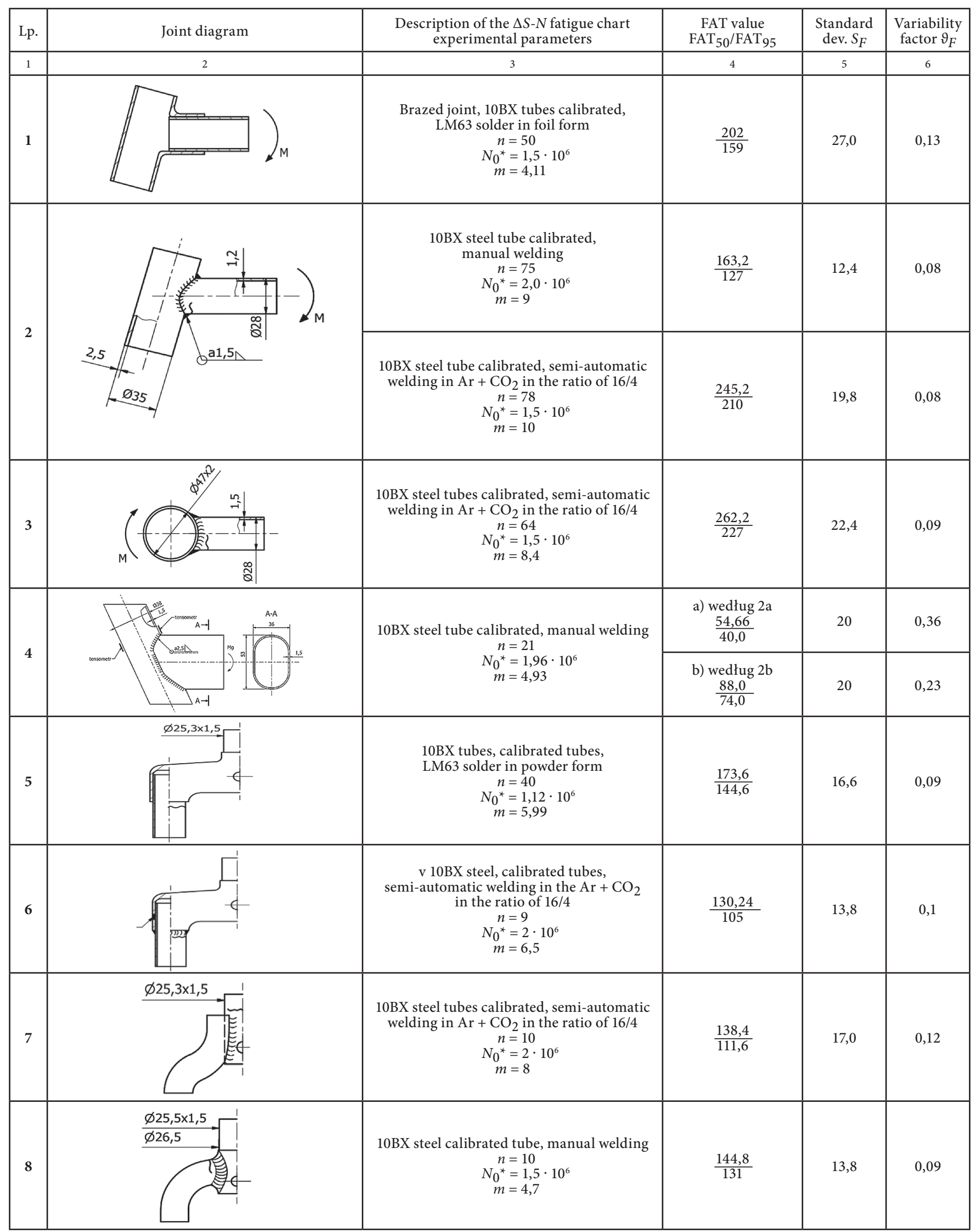

$n$ - number of fatigue tests, $N_{0}{ }^{*}$ - number of cycles corresponding to the point of refraction of the experimental fatigue chart, $\mathrm{m}$ - exponent of power in the formula (1) of the fatigue chart 
The comparison of these charts shows a significant difference between them. The charts determined according to the chart in Figures $2 \mathrm{a}$ and $2 \mathrm{~b}$ lie above the plot determined experimentally, which means that the fatigue properties determined according to the FITNET procedures are "inflated". The above is important in the calculation of fatigue life of structural elements, resulting in a higher than experimental durability. Higher incompatibility with experimental (1) is shown by the fatigue chart (3) (Fig. 6) determined according to the chart from Fig. 2b, which indicates the desirability of determining FITNET charts according to the chart in Fig. 2a.

The relationship between charts 1,2 and 3 described above in Fig. 6 occurs when the inflection point of the fatigue chart $\Delta S-N$ determined experimentally corresponds to the number of cycles less than $5 \cdot 10^{6}\left(N_{0}^{*}<5 \cdot 106\right)$ and the value of the $\mathrm{m}_{\mathrm{EX}}>3$ coefficient.

The analysis of the abovementioned cases is made possible by data for selected structural elements listed in table 3 . From the data contained in table 3 in col. 3 it follows that for joints: 1, 2b, 3, 5 and 8 the above-mentioned case occurs, it means that the charts have been developed on the basis of FITNET procedures, the fatigue properties are overstated in the description as compared to the experimental data. In all examined joints, it was found that the value of the coefficient $\mathrm{m}_{\mathrm{EX}}>3$. Complementing this data on the value of examinations of welded joints available to authors, a chart of the frequency of the occurrence of the m-factor of Fig. 7 was drawn up.

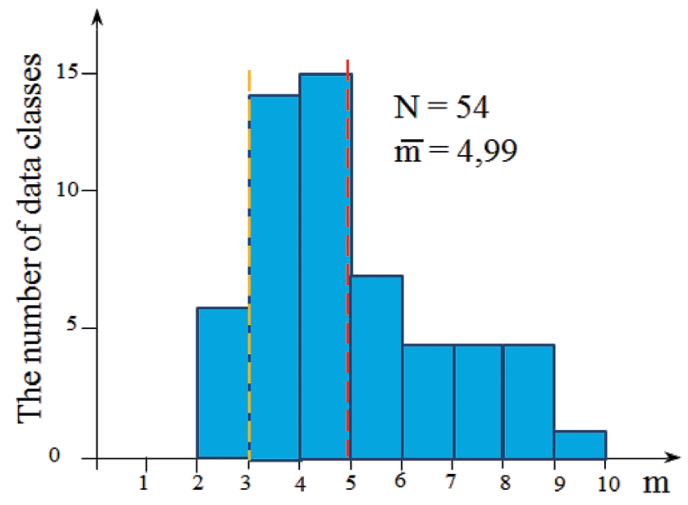

Fig. 7. Histogram of the occurrence of the value of the factor $m$ in the fatigue chart equation $\Delta S-N$ of welded joints

This histogram shows that the value of $m=3$ for normal stress variables adopted in FITNET procedures is in the lower limit of the analyzed 54 cases, for which the average $\bar{m}=4,99$.

The quality of the welded tubular joints performance is evidenced by the size of the dispersion of test results characterized by the values of the standard deviation $s_{F}$ (Table 3 , Col. 5) and the value of the coefficient of variation $\vartheta=s_{F} / F A T_{50}$. The data contained in columns 5 and 6 of table 3 show that the coefficients of variation $\vartheta_{F}$ are close to 0,1 for all considered joints, apart from the consciously accepted for analysis in this article, joint 4 , for which the spread is significant, mainly due to the applied manual welding technology. Charts of probability distributions of FAT values for spliced joints included in
Table 3, shown in Fig. 8, enable fatigue calculations of bonded elements in probabilistic terms.

In addition, the data concerning joint 2 results in a significant impact of welding technology on the value of the FAT parameter, which results in more than 1.5 -fold increase in fatigue strength of semi-automatically welded joints in the $\mathrm{Ar}+\mathrm{CO}_{2}$ envelope in relation to the strength of manually welded joints.

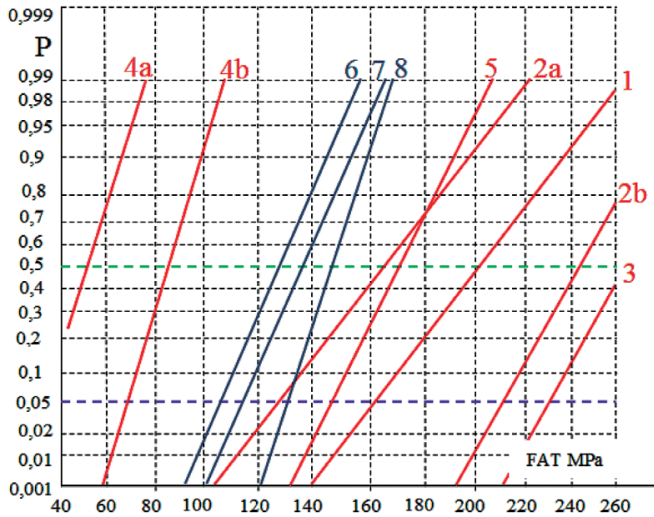

Fig. 8. FAT value probability distributions for the bonded joints from table 3

Based on formula (1) and knowledge of FAT values for $N_{F}=2 \cdot 10^{6}$, a formula for the dependence of $\Delta S-N$ can be determined in the form:

$$
\frac{\Delta S^{3}}{N}=\frac{(F A T)^{3}}{2 \cdot 10^{6}}=C
$$

In the literature, there are grids for determining fatigue charts based on the formula (5). An example of such a grid with marked charts for joints $2 \mathrm{a}$ and 4 is shown in Fig. 9.

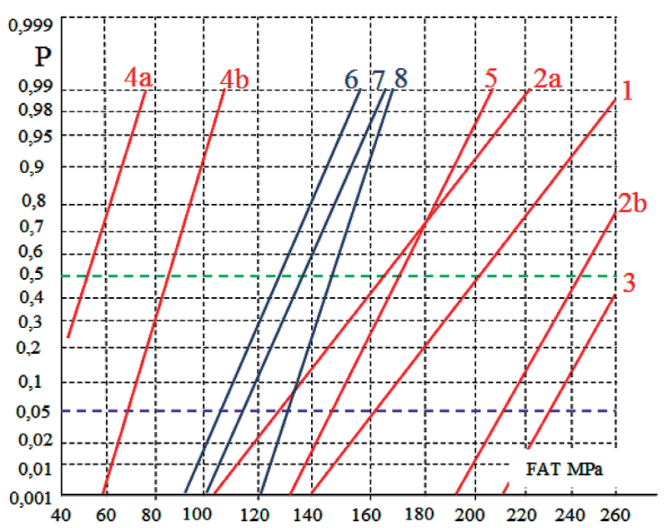

Fig. 9. Grid for plotting $\Delta S-N$ charts according to FITNET procedures

\section{CONCLUSION}

Comparative analysis of the methods of description of fatigue charts of bonded joints performed in point 4 results in the following conclusions: 
a) Fatigue charts $\Delta S-N$ determined in accordance with FITNET procedures, in the case of the welded joint analyzed in point 3 , significantly differ from fatigue charts determined experimentally. The value of these differences depends mainly on the method of determining the FAT parameter and the arbitrary assumption of the value of the coefficient $m=3$ in the formula (1) different from the value of the coefficient $m=4,93$ determined experimentally. Assuming the assumption of a safe method of fatigue calculation, it is recommended that two methods of determining the FAT parameter described in point 2 should be used with the results of tests determining the $\Delta \mathrm{S}-\mathrm{N}$ chart in the HCF range (according to Fig. 2a).

b) The conclusion from point a has been confirmed to varying degrees in the analysis of parameters of bonded joints listed in Table 3, which result in differences in $m=3$ according to FITNET and experimentally determined (column 3, table 3), which also confirms the histogram of the experimental factor distribution $m$ in Fig. 7.

c) The data contained in table 3 regarding the values of the FAT parameter (standard deviation $s_{F}$ and coefficient of variation $\vartheta_{F}$ ) enable fatigue calculations of the bonded construction joints in a probabilistic approach.

d) The analysis of the value of the coefficient of variation $\vartheta_{F}$ for individual joints shows that the quality of joints, measured by the value of the coefficient $\vartheta_{F}$, is comparable.

\section{REFERENCES}

1. Ligaj B.: Effect of stress ratio on the cumulative value of energy dissipation, Key Engineering Materials, vol. 598, pp. 125-132, Swidzeland, 2013.

2. Manson S. S.: Fatigue; Complex Subject - Same Simple Approximations, Experimental Mechanics, vol. 5, No 7, 1965.

3. Sempruch J., Strzelecki P.: Experimental Verification of the Analytical Method for Estimated S-N Curve in Limited Fatigue Life, Materials Science Forum Vol. 726, pp. 11-16, Switzeland, 2012.

4. Kocańda S., Szala J.: Podstawy obliczeń zmęczeniowych, PWN, Warszawa, 1997.

5. Hobbacher A. F.: Recommendations for Fatigue Design of Welded Joints and Components, International Institute of Welding, Springer ISBN: 978-3-319-23756-5, 2016.

6. Kacak M., Webster S., Janosch J. J., Ainsworth R. A., Koers R., FITNET, Fitness for Service Procedure - Final Draft MK 7, 2006.

7. Fricke W., Petershagen H., Paetzold K.: Fatigue Strength of Ship Structures, GL-Technology, Hamburg, 1997.
8. Strzelecki P., Sempruch J.: Verification of analytical models of the $S-N$ curve within limited fatigue life, Journal of Theoretical and Applied Mechanics - 2016, 54, 1, pp. 63-73, ISSN: 1429-2955, 2016.

9. Boroński D., Szala J.: The hybrid strain analysis in fatigue loading conditions, Proceedings of the 8th International Fatigue Congress, Stockholm, EMAS, 2002.

10. Ligaj B., Szala G.: Fatigue life calculation in conditions of wide spectrum random loadings - the experimental verification of a calculation algorithm on the example of 41Cr4 steel, Materials Science Forum, vol. 726, pp. 17-26, Switzeland, 2012.

11. Szala G., Ligaj B.: Description of cyclic properties of steel in variability conditions of mean values and amplitudes of loading cycles, Materials Science Forum vol. 726, pp. 69-76, Switzerland, 2012.

12. Polish standard PN-H-04334: Badania niskocyklowego zmęczenia metali, 1984.

13. Kozak J., Gorski Z., Fatigue strength determination of ship structural joints Part I Analytical methods for determining fatigue strength of ship structures, POLISH MARITIME RESEARCH, vol.18, Issue: 2, 2011, pp. 28-36, DOI: 10.2478/ v10012-011-0009-8.

14. Kurek M., Łagoda T., Katzy D., Comparison of Fatigue Characteristics of some Selected Materials, MATERIALS TESTING, vol. 56, Issue: 2, 2014, pp. 92-95, DOI: $10.3139 / 120.110529$.

15. Henry J., Huther M., Recommendation for hot-spot stress definition in welded joints, Dok. MIS XIII-1416-91.

16. ROMEIJN A., The fatigue behaviour of multiplanar tubular joints, HERON nr 3/1994.

17. Rizzo C., Tedeschi R., Experimental fatigue tests of a typical structural detail (beam n.1\&2), International Maritime Association of the Mediterranean, 2002 Congress, Crete13-17 May 2002, paper no. 21.

18. Rizzo C. M., Tedeschi R. A., Fatigue strength of a typical ship structural detail: tests and calculation methods, Fatigue \& Fracture of Engineering Materials \& Structures, vol. 30, Issue: 7, 2007, pp. 653-663.

19. Yousefi F., Witt M., Zenner H., Fatigue strength of welded joints under multiaxial loading: experiments and calculations, Fatigue \& Fracture of Engineering Materials \& Structures, vol. 24, Issue: 5, 2001, pp. 339-355. 
20. Kudryavtsev Y.F., Statnikov E.S., Residual stresses and fatigue strength of welded joints. Experimental studies and calculation, Conference: International Conference on Fatigue of Welded Components and Structures - 7th International Spring Meeting of the Societe-Francaise-de-Metallurgie-et-deMateriaux Location: SENLIS, FRANCE Date: JUN 12-14, 1996, pp. 293-300.

\section{CONTACT WITH THE AUTHORS}

Grzegorz Szala

e-mail:gszala@utp.edu.pl

Bogdan Ligaj

e-mail:bogdan.ligaj@utp.edu.pl

University of Technology and Science in Bydgoszcz Mechanical Engineering Faculty

al. Prof. S. Kaliskiego 7

85-796 Bydgoszcz

Poland 